\title{
The International Transmission of Volatility Shocks on an Emerging Economy: The Case of Malaysia
}

\author{
Said Zamin Shah ${ }^{a}$ \\ Islamia College University \\ Ahmad Zubaidi Baharumshah ${ }^{b}$ \\ INCEIF \\ Rusmawati Saidc \\ Universiti Putra Malaysia \\ Rafiqa Murdipi ${ }^{\mathrm{d}}$ \\ Universiti Putra Malaysia
}

\begin{abstract}
This study examines the effects of global economic policy uncertainty (EPU) on Malaysia's macroeconomic indicators. Three substantive findings emerged from our inquiry based on a multivariate generalized autoregressive conditional heteroscedasticity (GARCH) model: (1) Domestic uncertainty - in nominal and real terms - seems to have no material impact on the macro-economy after controlling for global uncertainty. (2) Fluctuations in the global EPU are more important than domestic uncertainty in predicting a country's macroeconomic variables, particularly output and $\mathrm{CPI}$-based inflation. The macroeconomic variables carry signs as per theoretical expectation. (3) The model predicts that external shocks exhibit a much larger impact on macroeconomic variables than those shocks originating from domestic markets. The results have deepened our insight on how the real variables correlate with external uncertainties and the fitful recovery in the recent past.
\end{abstract}

Keywords: Economic policy uncertainty, output growth, inflation, multivariate GARCH JEL classification: E32, E52, F42

a Department of Economics, Islamia College University, Peshawar, Khyber Pakhtunkhwa, Pakistan. Email: szshah@icp.edu.pk

b INCEIF, Lorong University A, 59100 Kuala Lumpur, Malaysia. Email: zubaidi@upm.edu.my (Corresponding Author). The author is also attached to Universiti Putra Malaysia.

c Department of Economics, Faculty of Economics and Management, Universiti Putra Malaysia, 43400 UPM, Serdang, Selangor, Malaysia. Email: rusmawati@upm.edu.my

d Department of Economics, Faculty of Economics and Management, Universiti Putra Malaysia, 43400 UPM, Serdang, Selangor, Malaysia. Email: rafiqa@iium.edu.my

\section{Acknowledgement}

* We thank the Editor and an anonymous referee of this journal who generously helped us to improve this paper. Any remaining errors/omissions are solely ours. The authors also thank Universiti Putra Malaysia [Grant Putra, Project No: 9440900] for the financial support of this research project.

Article Info: Received 30 November 2018; Revised 22 May 2019; Accepted 5 September 2019

https://doi.org/10.22452/MJES.vol56no2.4 


\section{Introduction}

After the publication of Bloom's (2009) seminal paper, a new strand of literature has ignited to prove that (positive) uncertainty shocks have serious consequences on real variables, particularly for every advanced economy. Sudden jumps in policy uncertainty generate rapid drops in output and other macroeconomic variables that represent an economy as the extensive empirical works suggested. Slow economic recovery in the US and Europe (see, inter alia, Choi, 2018; Istiak \& Serletis, 2018; Leduc \& Liu, 2016) are linked to economic policy uncertainty (EPU hereafter) concerning policy action or inaction. The literature has grown dramatically, especially after the onset of the global financial crisis (GFC) in 2008. Mounting evidences are suggesting that the Great Recession that originates from the US is associated with dramatic increases in both inflation and output growth uncertainty. The GFC brought to an end to the "Great Stability" period and emerging markets (EMs) are now uncertain about the growth challenges ahead. ${ }^{1}$

Heightened uncertainty shocks tend to depress corporate investments (Gulen \& Ion, 2016) and this in turn adversely affects the overall economic performance. A series of papers (Mumtaz \& Theodoridis, 2015; Ozturk \& Sheng, 2018; and references therein) denotes that EPU, an index of policy related uncertainty at country level, is likely to be the driving force of recession (Baker, Bloom, \& Davis, 2016). They claimed that the depth and length of the crisis are determined by the level of the uncertainty, among others. Elevated global uncertainty shocks have long lasting detrimental effects on industrial production (fall in GDP). Evidence from prior studies shows EMs suffer a more severe fall in investment and private consumption than the advanced economies because of less-developed financial and other institutions. Responses of macro variables (e.g. exchange rates) to uncertainty distresses are not homogenous across countries and time. Besides that, little is known with regard to the extent to which the spillover effects differ across the types of shock (e.g., economic versus financial) and across countries (developed versus developing).

There are three major transmission channels whereby uncertainty affects macroeconomic outcome. The first channel illuminates how uncertainty affects investment decisions in an economy. The wait-and-see idea premiered by Bernanke (1983) explained the adverse effects of uncertainty on investment. The second shows the relationship between private consumption and EPU, and the final is on how the uncertainty affects a country's financial variables. ${ }^{2}$ Both consumption and investment expenditures constitute a large proportion of gross domestic product (GDP). The consequences of positive policy shocks is to lower output growth. Here, the assumption is that a negative relationship exists between EPU and demand-pull factors. Sluggish investment growth observed after the Asian financial crisis (AFC) of the late 1990s is largely due to increase in uncertainty in the financial markets at the regional level. The

\footnotetext{
The risk of sudden stops and reversal has adverse effects on growth and financial stability.

The euro debt crisis reveals that EPU shock may hit fragile countries like the GIIPS countries (Greece, Italy, Ireland, Portugal and Spain) much harder compared to the other stable Euro countries (Germany or France). Uncertainty holds back investment and consumption.
} 
financial channel is vital in the transmission of uncertainty shocks (Akinci, 2013), with a much greater role during recession and in short run shocks. Evidently, her estimates were found to be indistinguishable between alternative estimation methods (bias corrected LSDV or GMM).

A recent strand in the literature finds financial globalisation has made small economies susceptible to various types of spillover from the dominant economies, namely, the US, Japan and China. It is widely acknowledged that uncertainty of all types are countercyclical. Ozturk and Sheng's (2018) study shows that global uncertainty (constructed from 45 advanced and emerging market economies) has the potential to influence county-specific uncertainty through trade and financial channels. Isolating the role of foreign from country-specific uncertainty factors on economic growth can be a challenging task. It is still an open question and can only be resolve empirically. The proposition that global factors matter for country-specific uncertainty is still unresolved by respective literature.

Dungey and Osborn (2014) modelled the international linkages between two major developed economies (namely, the US and Euro area) via an open economy framework. The US is the world's leading economy (representing around $20 \%$ of the global output) but the empirical findings reveal that it is not immune from foreign shocks. They also untangled a feedback causal relationship between the US and Euro area that applies for inflation and interest rate and real exchange rate, despite the fact that monetary policy is focussed domestically. Dungey and Osborn's (2014) findings refute the fact that the US, a dominant economy is least affected by global economic conditions. Fontaine, Didier and Razafindravaosolonirina (2017) drew our attention when they corroborate that EPU that originates from China impedes US EPU and economic growth during highly volatile regime. Of note, Zhang, Lei, Ji and Kutan (2019) found that EPU originating from China is becoming more influential in several key international markets (e.g. stock, credit, energy and commodities) with the US maintaining its dominant position in these markets. There is supportive evidence that international markets affect real sectors of the economy even for frontier markets with sound macroeconomic and financial preconditions.

Our primary goal in this paper is to determine to what extent the conclusions derived from the above-mentioned studies apply to Malaysia. Currently, Malaysia is undergoing serious economic difficulties because of a heightening fiscal burden in the aftermath of the global financial crisis (GFC). It has also shifted from a fixed to a more flexible exchange rate regime. ${ }^{3}$ Building upon previous research works, we estimate the response of real macroeconomic variables to changes in global policy shocks. Near zero interest rate policy (near-ZIRP) by the US Federal Reserve System (Fed) and the USChina trade conflict are some examples of external spillovers from global EPU. We select Malaysia for this study because of the high debts, averaging more than $50 \%$ of GDP over the past decade. The fragile state of the economy makes growth prospects more

3 Studies have shown that the two regimes exhibit similar output response but different inflation and interest rates responses. After the pegged regime, Malaysia's exposure to foreign shocks increased significantly. More recently, commodity prices and global activities' shocks drive the economy (see Raghavan \& Athanasopoulos, 2019). 
vulnerable to undue pressures of the EPU. Moreover, uncertainty about fiscal policy and the credibility of economic policy are high. To this end, we rely on a novel proxy constructed by Baker, Bloom and Davis (2016), hereafter BBD to investigate the issue. Based on a variety of policy-related indicators, BBD's index has emerged as a popular barometer to gauge the impact of external shocks. We use this measure (number of citations on uncertainty in press) to contribute to our understanding on the dynamics of macroeconomic variables such as growth and its volatility. Overall, our findings do not reject the uncertainty-based explanation of business cycles. Results highlight the importance of public policies aimed at alleviating the effects of uncertainty.

Our primary goal is to recognise uncertainty as a potential drag on growth in an EM. It displays clear evidence that external shocks are more harmful to the economy when the home country is in a fragile state; see Fontaine et al. (2017). Close in spirit to papers by Grier, Henry, Olekalns and Shields (2004), and Jones and Olson (2013), we choose to do the analysis within the context of a multivariate BEKK-GARCH $(1,1)$ $M$ (hereafter BEKK-GARCH-M) and augmented the model with global EPU shocks as control variable. We apply the model to gauge the magnitude of spillovers in mean and variance of the macroeconomic variables from a frontier market. ${ }^{4}$ Fluctuations in global EPU are more important in predicting a country's macroeconomic variables, particularly output and CPI-based inflation.

\section{Relevant Literature}

Literature on the host subject is not limited to those articles mentioned in the previous section. For instance, Istiak and Serletis (2018) contributed to this literature by showing that news-based EPU constructed by BBD (2016) is countercyclical and that the effect seems to increase with size of the shock. They found that the responses to real output for the G7 countries are country specific. Overall, the results of their inquiry favour policies that remove uncertainty to minimise the welfare costs linked to uncertainty. A powerful government that is transparent (both in the fiscal and monetary design) and follows predictable and productive regulations has the potential to benefit society. Departing from the existing study, Choi (2018) examined the impact of financial shocks from the US on uncertainty-output nexus. His work focusing on the EMs unbundled financial shocks from the US - measured by implied volatility of the S\&P 500 index, VIX - have substantial impact on the EMs economic performance without even having any significant impact on the US real economic activities. The effect of the shocks described in Choi (2018) differs from prior studies. According to the author, US financial uncertainty shocks hinder EMs' output and the negative effect appears to be larger than the ones experienced by the US. To explain this puzzling phenomenon, Choi relied on cross-border capital flows and the increasing cost of external financing with heightened global uncertainty to convince his empirical findings. ${ }^{5}$ Therefore, we may conclude

4 Balli, Hajhoj, Basher and Belkacem (2015) found that the US is an important transmitter of shocks although the extent of the impacts differs markedly across the surveyed countries. For Malaysia, the intensity in term of variance ratio is around $14 \%$.

5 A number of papers observed the EMs risk premium are highly correlated with international factors. 
that the US is a dominant transmitter of uncertainty. Policymakers aiming to formulate effective macroeconomic policy in the interconnected global environment should take consideration of the findings. ${ }^{6}$

Recent crisis seems to reveal that price stability is not enough to achieve financial stability. In addition, we learn that interest rate policy alone may not be enough to achieve financial stability. The evidence suggests that the Great Recession was likely an acute manifestation of the toxic interaction between economic uncertainty and financial shocks. Bloom (2009) has underscored this point. The latter finds that EPU and financial market stress accounted for almost $50 \%$ of international spillovers. As with the vast majority of the empirical studies, they agree, that EPU negatively affects firms' capital expenditure. Both consumers and investors are unwilling to spend and invest during periods of elevated degree of EPU in the economy.

Krol (2014) showed that both home and US EPU increase exchange rate volatility (for both EMs and developed economies) particularly during bad economic times, posing a real threat for real activities. There is virtually no evidence that the uncertainty originating from US affects the volatility of the less integrated EMs. The major driving force of exchange rate volatility is the level of country-specific uncertainty and the two correlate negatively. Therefore, an elevated EPU leads to decline in growth since it tends to favour the wait-and-see strategy. Uncertain about future sales and profits, firms are likely to postpone production and investment until uncertainty is resolved. Besides that, firms prefer to hold more cash when uncertainty increases. Demir and Ersan (2017) found firms in BRIC countries (BRICS: stands for Brazil, Russia, India, China and South Africa) increase cash holdings in an uncertainty environment. Specifically, firms will increase their cash holding when uncertainty about government policies at the global level increases. The so-called real options theory make it profitable to postpone their investment plans to a more certainty period. Similarly, cash holding of East Asian countries increased significantly because of higher cash flow risk and lower growth opportunities in the post-Asian financial crisis period (Song and Lee, 2018). In both cases, they adversely affect corporate investments and national output as well.

The evidence we derive for Malaysia is in harmony with existing literature, resulting in a significant drop in real growth but a rebound in price stability. These dynamics are also consistent with predictions of the model incorporating global inflation uncertainty that exhibit a strong impact of foreign uncertainty shocks on domestic inflation and output growth. However, the evidence from global inflation uncertainty indicates that Malaysia seems to suffer a much higher rise in inflation and a significant increase in output growth following global inflationary shocks. We uncover evidence that shocks in domestic nominal and real uncertainties keep the domestic macroeconomic performance unaffected. It is worth mentioning that sovereign credit ratings set the tone for gauging borrowing cost in the international markets both for sovereign state and financial institutions operating in that state. It is important for simulating investment and supporting growth, particularly in the developing

6 The literature acknowledge that there is no objective measure of uncertainty and so economists rely on several different proxies. Jurado, Ludvigson and $\mathrm{Ng}$ (2015) constructed an alternative measure of macroeconomic uncertainty index based on 132 macro series to confirm that uncertainty is counter-cycle. 
economies. Moreover, EPU affects substantially bank's non-performing loans and loan loss provisions adversely.

Our investigation throws new light on the importance of various cross-country shocks on Malaysia's output, thereby endorsing contributions of those reported earlier in Choi (2018) and Ozturk and Sheng (2018). Choi (2018) who quantified the impact of US financial uncertainty on 18 EMs confirmed that the effect of US uncertainty shocks on investment and consumption are substantially larger in magnitude than that observed in the developed economies. ${ }^{7}$ According to Choi (2018), EMs with less sophisticated institutions tends to suffer deep and prolong impacts from uncertainty shocks. Spillovers aggregates across countries are present and important. To reduce the negative impact generated by uncertainty shock, monetary and fiscal policy actions have to alleviate the impact of credit constraints facing firms.

Aastveit, Bjørnland and Thorsrud (2016) reported that if EPU is high, then it decreases the effectiveness of monetary policy because it weakened the effect of the policy on output. A few studies have analysed the effects of macroeconomic uncertainty on economic growth (Baharumshah \& Soon, 2014), but none of them have accounted for the direct effects of foreign shocks on the domestic economy. Numerous studies discuss the effect of EPU on the overall economic prosperity from the perspective of structural vector autoregressive (VAR); see among others Choi and Shim (2019), Jurado et al. (2015), Leduc and Liu (2016), Mumtaz and Surico (2018) and Shah, Baharumshah, Law and Habibullah (2017). However, the above-mentioned studies adopted a different version of VAR specification - as workhorse model - to estimate the effect of uncertainty shocks of a variable on the other aggregate variables. By employing the BBD indicator, Choi (2018) unearthed shocks to US EPU (one standard deviation) is followed by fall in industrial production $(-0.12 \%)$ and prices $(-0.06 \%)$. In closer spirit with Colombo (2013), Choi (2018) considered the broad-based measure of uncertainty for Korea and found that policy uncertainty does not have much material effect on real variables. He found that the US uncertainty measure has a substantial impact on the output of the EMs (via the credit channel). Results from structural VARs appear to be consistent for large groups of countries labelled as EMs and the current economic difficulties that they are currently facing. Meanwhile, the author observed that an elevation in the volatility of the S\&P stock futures index (VIX) has no material impact on the dynamics of US output. ${ }^{8}$

Interactions among economies have grown in intensity since 2000 by a wave of globalisation, characterised by rapidly growing international trade, capital movements and information flows (Baharumshah, Chan, \& Fountas, 2008; Munir, Kok, Lean, \& Teplova, 2018). The effect of an increase in the US (or European Union) EPU is not confined to its national boundaries but can spillover to the rest of the world; see among others, Colombo (2013), Liow, Liao and Hwang (2018), Trung (2019) and Tsia (2017).

7 Mumtaz and Surico's (2018) study showed that uncertainty about debt have large and persistent effect on output, consumption and investment. They unfold that policy uncertainty explained around $25 \%$ of fluctuation in real activities, with public debt uncertainty shock making the largest contribution.

8 VIX index is widely used in the empirical papers as a proxy of uncertainty; see Bloom (2009). Hoque and Zaidi (2019) demonstrated that global EPU has strong negative impacts on Malaysia's sectorial stock market returns. 
Recent papers record that foreign shocks explain a major share of the variance in all countries particularly shocks that is common worldwide. Foreign shocks can lead to increase in firm's cash holding due to precautionary savings and investment delays. Global shocks explain a much higher percentage of the business cycles variation than regional shocks. The financial crises (e.g. the US subprime mortgage crisis in 2007, the collapse of Lehman Brothers in 2008, and the European debt crisis in 2010) were not merely national or regional financial crises but represent financial events that relentlessly affect the economy across the globe. The transnational effect of EPU occurs almost instantaneously across the globe, mostly through the financial networks. They produce the worst recession since the Great Depression and had the effect of a longer recovery time. All these explain why policymakers have to focus more on global development to ensure domestic stability and a sustainable growth path.

In terms of performance, the literature discovered that domestic and foreign uncertainties differ in inducing the behaviour of macroeconomic and financial variables. For example, Krol (2014) in his assessment on the subject disclosed that domestic and foreign (US) EPU in highly integrated economies are more binding, particularly during bad economic conditions. They allude EPU has a negative impact on real economic activity via the exchange rate uncertainties-output nexus for advanced countries. According to Krol, only home-country EPU (foreign uncertainty) significantly increased exchange rate volatility for the EMs in bad economic times (p. 252). Evidence shows that greater exchange rate uncertainty through the financial channel reduces productivity, investment, consumption, international trade and economic growth.

To the best of our knowledge, our paper is the first to examine the macro-dynamic consequences of global uncertainty shocks on a small emerging economy - Malaysia. Instead of EPU, some studies (Choi, Furceri, Huang, \& Loungani, 2018) have looked at the impact of US financial uncertainty shocks (measured by VIX) on productivity. Choi et al. (2018) in particular argued that in the presence of imperfect credit market, an increase in aggregate uncertainty - as measured by stock market volatility or BBD's (2016) EPU index - adversely affects the macroeconomic performances of the EMs but not on the US economy. Moreover, it is acknowledged that stock market volatility depends on EPU shocks. Policymakers in the developing world are concerned about the adverse effect of an exit policy from the unconventional monetary policy (quantitative easing) if such a move is accompanied by spikes in VIX. To sum up, the VIX index serves as a real-time barometer for EMs, independent of the US economy.

Our study makes at least three major contributions. First, we extend the economic consequences of EPU to an EM, where empirical evidence remains scarce. The focus is on global EPU's effect on macroeconomic performance. Secondly, compared to the advance countries, impact of EPU on the Malaysian economy is significant and policymakers cannot ignore that the shocks can be large and long lasting. Finally, monetary (inflation) instability hinders investments spending due to uncertainty in the macroeconomic environment. Firms finding it difficult to gauge their future cash flows in the context of increasing uncertainty may decide to hold more cash, placing premium on liquidity in times of major economic and/or political events.

The rest of the paper is organised as follows. In the next section, we present the econometric methodology. Section 4 provides a brief discussion on the data and data 
sources. Section 5 is devoted to the empirical results and discussion. The last section summarises the major findings and presents some policy implications.

\section{Econometric Methodology}

We apply Engle and Kroner's (1995) BEKK-GARCH-M to model the spillover effects and dynamic interrelationships of domestic macroeconomic uncertainty, global EPU and domestic macroeconomic performance. In spirit, our implementation of the model is similar to Jouini and Harrathi (2014). Our study is distinctive in the sense that it considers the volatility spillover from global uncertainty to an EM through relatively advanced GARCH family model, which is the object of interest. The specification of conditional mean equation is as follows:

$$
x_{t}=\mu+\sum_{i=1}^{p} r_{i} x_{t-i}+\psi \sqrt{h_{t}}+\varepsilon_{t}
$$

where $x_{t}$ is a $(3 \times 1)$ column vector given by $x_{t}=\left[\begin{array}{c}\pi_{t} \\ y_{t} \\ e p u_{t}\end{array}\right] ; \mu=\left[\begin{array}{c}\mu_{\pi} \\ \mu_{y} \\ \mu_{e p u}\end{array}\right]$ is a $(3 \times 1)$ vector of constants, $\Gamma_{i}=\left[\begin{array}{ccc}\Gamma_{\pi \pi, i} & \Gamma_{\pi y, i} & \Gamma_{\pi \text { epu,i }} \\ \Gamma_{y \pi, i} & \Gamma_{y y, i} & \Gamma_{y \text { epu,i }} \\ \Gamma_{\text {epu } \pi, i} & \Gamma_{\text {epuy,i }} & \Gamma_{\text {epuepu,i }}\end{array}\right]$ is the $(3 \times 3)$ vector of autoregressive parameters with $i=1,2,3, \ldots, p ; \psi$ is the uncertainties (in-mean coefficients) matrix as:

$\psi=\left[\begin{array}{ccc}\psi_{\pi \pi, i} & \psi_{\pi y, i} & \psi_{\pi e p u, i} \\ \psi_{y \pi, i} & \psi_{y y, i} & \psi_{\text {yepu,i }} \\ \psi_{\text {eрu } \pi, i} & \psi_{\text {epu } y, i} & \psi_{\text {epu } е р u, i}\end{array}\right] ; \quad \sqrt{h_{t}}=\left[\begin{array}{c}\sqrt{h_{\pi t}} \\ \sqrt{h_{y t}} \\ \sqrt{h_{\text {eput }}}\end{array}\right]$ and finally $\varepsilon_{t}=\left[\begin{array}{c}\varepsilon_{\pi t} \\ \varepsilon_{y t} \\ \varepsilon_{\text {eput }}\end{array}\right]$ is a $(3 \times 1)$ vector of residuals, assumed to be normally distributed with its corresponding conditional variance-covariance matrix $H_{t}=\left[\begin{array}{ccc}h_{\pi, t} & h_{\pi y, t} & h_{\pi \text { epu }, t} \\ h_{y \pi, t} & h_{y, t} & h_{y e p u, t} \\ h_{\text {epu } \pi, t} & h_{e p u y, t} & h_{e p u, t}\end{array}\right]$ with $\varepsilon_{t} \mid \Omega_{t-1} \sim N\left(0, H_{t}\right)$ and $\Omega_{t-1}$ is the information set up to time $t-1$. The diagonal elements $\left(h_{\pi, t^{\prime}} h_{y, t}\right.$ and $\left.h_{e p u, t}\right)$ in the $H$ matrix are the conditional variances of inflation, output growth and global EPU respectively. They are computed as one-step ahead forecasting error. Meanwhile the $h_{\pi y}$ and $h_{y \pi}$ are the conditional co-variances between inflation and output growth and between output growth and inflation respectively. Similarly, $h_{\text {лери }}$ and $h_{\text {ери } \pi}$ denote the conditional co-variances between domestic inflation and global economic policy uncertainty and between global macroeconomic policy uncertainty and domestic inflation respectively. Finally, $h_{\text {у ерu }}$ and $h_{\text {epu } y}$ exhibit the time-varying conditional covariances between domestic output growth and global policy uncertainty and between global policy uncertainty and domestic output growth respectively. 
In sum, we conclude here that the 3-dimensional BEKK-GARCH-in-mean model allows for the estimation of the mean-to-mean, the volatility-to-mean (risk premium) and the volatility-to-volatility spillovers. Notably, this study adopts the BEKK (name after Baba-Engle-Kraft-Kroner) approach of multivariate asymmetric BEKK-GARCH-M and the conditional variance and covariance is:

$$
H_{t}=C^{\prime} C+A^{\prime} \varepsilon_{t-1} \varepsilon_{t-1}^{\prime} A+B^{\prime} H_{t-1} B+D^{\prime} \omega_{t-1} \omega_{t-1}^{\prime} D
$$

where $H$ is the variance-covariance matrix, $C$ is a $3 \times 3$ triangular matrix, $A$ and $B$ are the $3 \times 3$ matrices of ARCH and GARCH coefficients, respectively. Matrix $D$ of order $(3 \times 3)$ is the conditional variance-covariance matrix. It accounts for the possibility of nondiagonal and asymmetry in the variance-covariance structure to allow for interactions between the variance and covariance. The significance of the off-diagonal parameters $\left(d_{i j}\right)$ indicate the presence of asymmetric relationship. ${ }^{9}$ Note that the parameters of the models estimated by the quasi-maximum likelihood method using regression analysis of time series (RATS). We assume that convergence occurs if the changes in the estimated coefficients are less than the 0.00001 (default value).

\section{Data Description}

To probe on the dynamic correlation between BBD's global EPU and economic growth (Table 1), we consider a sample period from 1997:1 to 2016:12. The sampling period is constrained by the availability of data but covers the 1997/98 Asian financial crisis, the 2007/08 global financial crisis and the subsequent sovereign debt crisis in southern Europe (April 2010). For robustness checks, we also run the model with global inflation as an alternative measure of global policy uncertainty, to focus more on the conventional monetary shocks. ${ }^{10}$ Prior studies have confirmed that one of the drivers of domestic inflation is global inflation. Given the close connection among inflation, its volatility and output growth (Friedman, 1977), we also estimate the model with US inflation as proxy of global inflation.

In order to model the autoregressive form of output growth rate, inflation rate and economic policy uncertainty rate in the conditional mean, we construct the return series as the first logarithmic differences. In addition, the output growth rate, denoted by " $y_{t}$ ", inflation rate as " $\pi_{t}$ " and economic policy uncertainty as " $E P U_{t}$ "11 are calculated below to guarantee the stationarity of each variable as:

9 We apply an array of residual diagnostic tests to select the appropriate model. Numerical convergence is set as priority for the estimated models. The test statistic rejects the null hypothesis that the off-diagonal elements in the variance-covariance matrix are simultaneously zero at the indicated significance level. It favours the full-fledge BEKK over the diagonal BEKK for the intended analysis in both models to confirm that Malaysia's inflation and output Granger-cause global uncertainty. We are grateful to an anonymous referee for pointing this out to us.

10 The US monetary policy shocks affects the short-term interest rate and exchange rate in EM quickly and strongly. For example, if the shock represent a contraction in the US monetary policy, the ringgit usually depreciates and this induces inflation with little delay (Maćkowiak, 2007).

11 BBD (2016) monthly policy-related index combined three index components. The first component quantifies the number of references to policy-related uncertainty in 10 leading newspapers. The second is the number of federal tax codes provisions set to expire in future years and the final is the extent of disagreement between economic forecasters over the future. 


$$
y_{t}=\ln \left(Y_{t} / Y_{t-1}\right) \times 100 ; \pi_{t}=\ln \left(C P I_{t} / C P I_{t-1}\right) \times 100 \text { and } E P U_{t}=\ln \left(E P U_{t} / E P U_{t-1}\right) \times 100
$$

The dataset on the monthly CPI-inflation and industrial production index (proxy for output growth) is taken from International Financial Statistics, International Monetary Fund. Monthly series has the advantage over using higher-frequency data as it avoids high-frequency noise.

\section{Empirical Results and Discussions}

We adopt the BBD (2016) global EPU index to study the dynamic interrelationships of domestic macroeconomic uncertainty, global EPU and domestic macroeconomic performance. Global EPU is constructed from a GDP-weighted average of national EPU index of 20 countries (available at www.PolicyUncertainty.com) and they accounted for two-thirds of the global output. A partial list of countries includes the US, UK, China, Japan and several from Europe. Interested readers may refer to the website for a full list of countries. It is a monthly series and available starting from January 1997. Time series plots of global inflation, global macro policy uncertainty, output uncertainty and inflation uncertainty are depicted in Figure 1. A visual inspection of the time-plot of

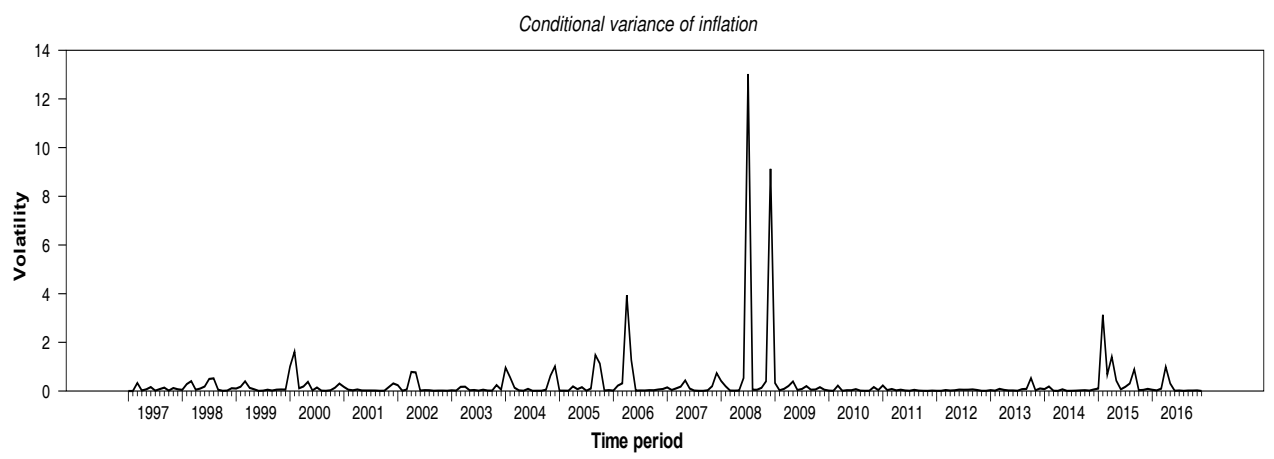

Figure 1. Time series plots of inflation uncertainty, output growth uncertainty and global economic policy uncertainty

(a) Inflation uncertainty

Source: Derived from MV-VAR-BEKK-GARCH-M

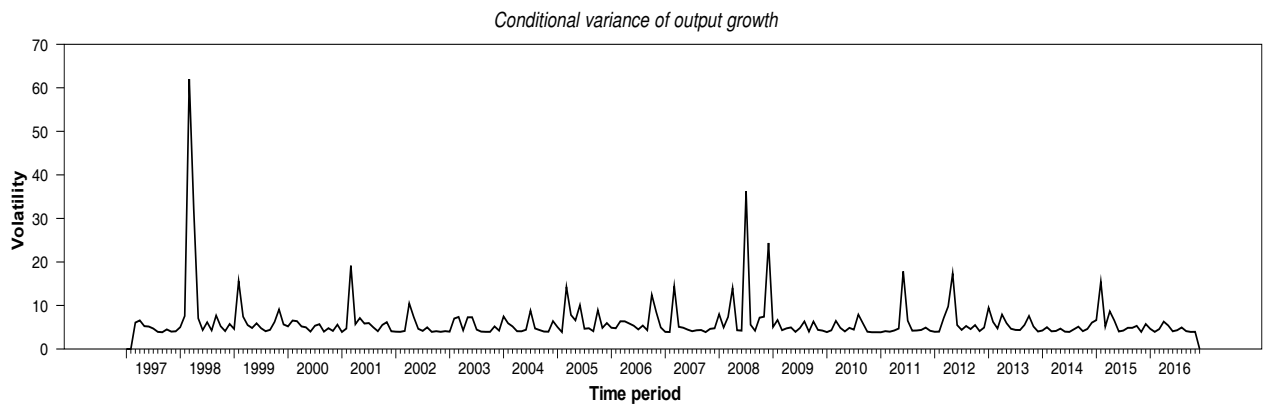

(b) Output growth uncertainty

Source: Derived from MV-VAR-BEKK-GARCH-M 


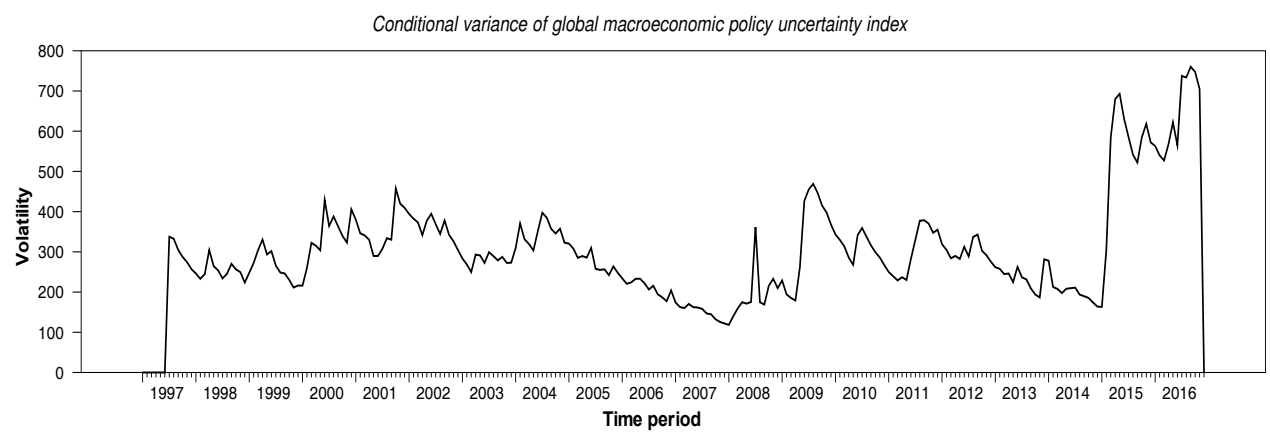

(c) Global macroeconomic policy volatility

Source: Derived from MV-VAR-BEKK-GARCH-M

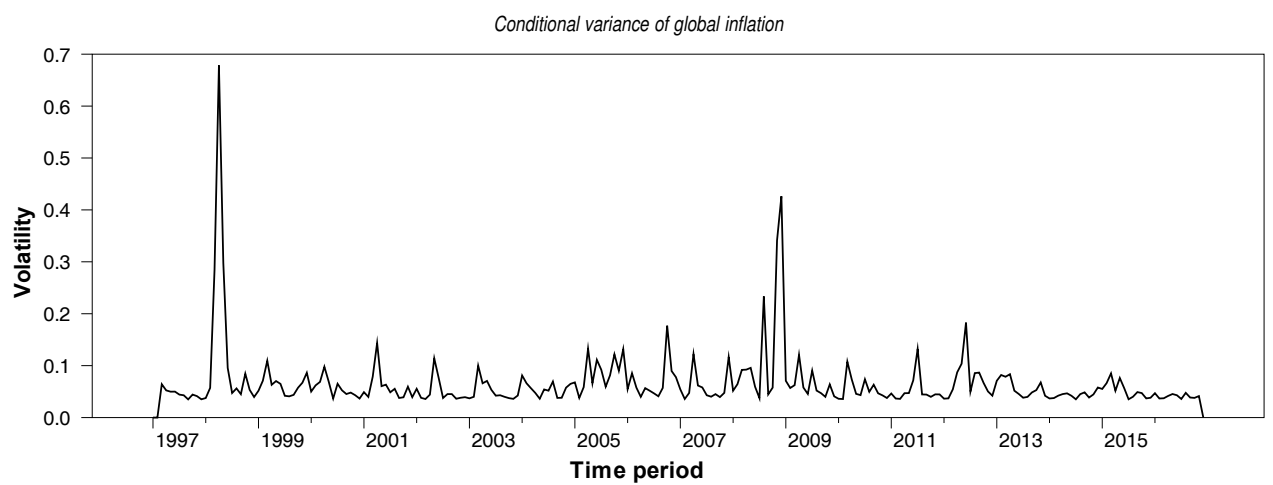

(d) Global inflation uncertainty

Source: Derived from MV-VAR-BEKK-GARCH-M

index reveals it rises sharply in reaction to the AFC, 9/11 terrorist attacks, US invasion of Iraq in 2003, GFC in 2008-09, concerns about Chinese economy in 2015 and the uncertainty associated with the Brexit referendum in June 2016.

Table 1 reports the results from the estimated multivariate GARCH model. ${ }^{12}$ Regarding the mean equation, there is significant lagged effect, suggesting further evidence on the persistence in inflation. Focussing on the volatility matrix (Table 1 Panel B), we arrive at several conclusions. There is a positive (negative) but insignificant effect of nominal (real) uncertainty, where inflation is the nominal variable and output is the real variable. Notice that there is no effect of domestic macroeconomic uncertainty on economic growth. To this end, we mention that Bredin, Elder and Fountas' (2009) found "macroeconomic uncertainty does not have an adverse impact on performance in most cases" (p. 223). As discussed in the introductory note, our model confirmed that there is a strong negative and significant effect of global EPU on macroeconomic

12 There are significant autocorrelations and $\mathrm{ARCH}$ effects in all the series. Results from unit root tests (available upon request) confirm that all the series achieve stationarity at level. 
Table 1. Estimates of BEKK-GARCH-M models [sample period: 1997.01 to 2016.12]

Panel A: Estimates of conditional mean equations

\begin{tabular}{|c|c|c|c|c|c|c|}
\hline \multirow[b]{2}{*}{ Constant } & \multicolumn{2}{|c|}{$\pi_{t}$} & \multicolumn{2}{|c|}{$y_{t}$} & \multicolumn{2}{|c|}{$e p u_{t}$} \\
\hline & $0.1360 * * *$ & (0.0109) & $0.3049 * *$ & $(0.1486)$ & $11.2056 * * *$ & (1.4560) \\
\hline$\pi_{t-1}$ & $0.3015^{* * *}$ & $(0.0546)$ & 0.2892 & $(0.3086)$ & $4.5038 * * *$ & (1.5393) \\
\hline$\pi_{t-2}$ & 0.0223 & $(0.0418)$ & $-0.7402 * * *$ & $(0.2022)$ & -2.1108 & (1.4166) \\
\hline$\pi_{t-3}$ & $0.0402 *$ & $(0.0226)$ & 0.3515 & $(0.3554)$ & $6.6495^{* * *}$ & (1.2006) \\
\hline$\pi_{t-4}$ & 0.0158 & $(0.0292)$ & $-0.8842 * * *$ & $(0.3214)$ & 4.1194* & (2.2054) \\
\hline$\pi_{t-5}$ & $-0.2568 * * *$ & (0.0389) & -0.0228 & $(0.3232)$ & $-8.1984 * * *$ & (1.8056) \\
\hline$y_{t-1}$ & $-0.0134 * * *$ & $(0.0032)$ & $-0.3986 * * *$ & $(0.0511)$ & $-0.4252 * *$ & (0.1945) \\
\hline$y_{t-2}$ & 0.0062 & $(0.0042)$ & 0.0148 & $(0.0448)$ & $-0.6256^{* *}$ & $(0.2580)$ \\
\hline$y_{t-3}$ & $0.0063 *$ & $(0.0035)$ & $0.3308 * * *$ & $(0.0457)$ & $-1.2014 * * *$ & $(0.2258)$ \\
\hline$y_{t-4}$ & -0.0050 & $(0.0038)$ & 0.0405 & $(0.0495)$ & 0.1142 & $(0.2030)$ \\
\hline$y_{t-5}$ & $-0.0082 * * *$ & $(0.0031)$ & 0.0176 & $(0.0432)$ & $0.6739 * * *$ & $(0.2362)$ \\
\hline$e p u_{t-1}$ & -0.0002 & $(0.0006)$ & 0.0046 & $(0.0064)$ & $-0.1542 * * *$ & $(0.0484)$ \\
\hline$e p u_{t-2}$ & $-0.0010 * *$ & $(0.0005)$ & -0.00001 & $(0.0050)$ & $-0.1529 * * *$ & $(0.0306)$ \\
\hline$e p u_{t-3}$ & -0.0002 & $(0.0005)$ & $-0.0218 * * *$ & (0.0068) & $-0.2279 * * *$ & $(0.0321)$ \\
\hline$e p u_{t-4}$ & 0.0001 & $(0.0006)$ & $0.0131^{*}$ & $(0.0066)$ & -0.0575 & $(0.0428)$ \\
\hline$e p u_{t-5}$ & 0.0006 & $(0.0006)$ & 0.0072 & $(0.0078)$ & $-0.0526^{*}$ & $(0.0307)$ \\
\hline
\end{tabular}

Panel B: Estimates of the uncertainty matrix $(\psi)$ for the BEKK-GARCH-M model

\begin{tabular}{lll}
\hline$\psi_{\pi \pi}$ & 0.0286 & $(0.0801)$ \\
$\psi_{\pi y}$ & -0.0034 & $(0.0205)$ \\
$\psi_{\text {пери }}$ & $-0.0410^{* * *}$ & $(0.0082)$ \\
$\psi_{\text {ул }}$ & 0.1810 & $(0.1547)$ \\
$\psi_{\text {yу }}$ & 0.0122 & $(0.0106)$ \\
$\psi_{\text {уери }}$ & $-0.0346^{* * *}$ & $(0.0082)$ \\
$\psi_{\text {ери }}$ & 0.0130 & $(0.2863)$ \\
$\psi_{\text {ериу }}$ & $0.2574^{* * *}$ & $(0.0477)$ \\
$\psi_{\text {ери ери }}$ & $-0.0377^{* * *}$ & $(0.0039)$ \\
\hline
\end{tabular}

Note: Figures in parentheses against the coefficients are the Bollerslev, Engle and Wooldridge (1988) robust standard errors. $*, * *$ and $* * *$ indicate that the coefficients are statistically significant at the $10 \%, 5 \%$ and $1 \%$ levels respectively.

variables. This justifies the inclusion of global EPU in the model. The negative sign means that greater global EPU stabilises Malaysia's CPI-based inflation (output growth). In contrast to the positive impact of global EPU on domestic inflation, uncertainty adversely affect the domestic real economic activity. The latter finding tends to support the precautionary motive of holding more cash in order to meet unanticipated contingencies (Baum, Chakraborty, Han, \& Liu, 2011). Gulen and Ion (2016) found that uncertainty associate with future policy and regulatory outcomes (BBD index) have negative effect on investment due to precautionary delays due to investment irreversibility. According to the authors' estimate, the increase in policy uncertainty 
between 2007 and 2009 accounted for around one-third of 32\% fall in capital investment. It supports the well-known real option theories, which denotes uncertainty increases the benefits from postponing investment.

Our analysis adds to the empirical literature by showing that the absence of the effect of domestic uncertainty on output growth reported in past studies is because of the exclusion of an important variable - the global EPU. It is marked out that it is the existence of foreign uncertainty shocks, which carry significant correlations with macroeconomic performance variables - inflation and economic growth. Precisely, our estimated results (Table 1) show that a 1\% increase in global EPU shocks reduces economic growth by 3\%. Caldara, Fuentes-Albero, Gilchrist and Zakrajšek (2016) singled out financial (Jurado et al., 2015) and uncertainty (e.g. BBD) shocks as potential drivers of business cycles since the mid-1980s. They showed that both financial and uncertainty shocks lead to a contraction of output ranging from 0.6 to $1 \%$ (much smaller than our estimates). In short, they create excessive fluctuation in EMs. The result highlights concerns regarding global macroeconomic fluctuations on the real economic activity of an EM economy. They concluded that, "the combination of financial and uncertainty shocks fully accounts for the severe contraction in real industrial output and the collapse of the stock market during the Great Recession" (p. 206).

In addition, based on the level of significance of the corresponding elements in the covariance matrix of BEKK-GARCH-M, we can easily reject the null of no cross-effect in favour of the alternative hypothesis at the usual significance levels (Table 2). The impact of lagged innovations and lagged conditional variances on their conditional volatilities are present. Conditional volatilities are highly connected to past conditional

Table 2. Estimates of the variance-covariance equations

\begin{tabular}{|c|c|c|c|c|c|}
\hline$C_{\pi \pi}$ & $0.0906 * * *$ & $(0.0132)$ & $\beta_{\pi e p u}$ & $-6.8575 * * *$ & (1.6652) \\
\hline$C_{\pi y}$ & $-0.3707^{* *}$ & $(0.1518)$ & $\beta_{y \pi}$ & $0.0102 * *$ & $(0.0047)$ \\
\hline$C_{y y}$ & $1.1410 * * *$ & (0.1194) & $\beta_{y y}$ & 0.0266 & $(0.0503)$ \\
\hline$C_{\pi \text { epu }}$ & 0.2366 & $(0.6590)$ & $\beta_{y \text { ерu }}$ & $0.8114^{* * *}$ & $(0.2053)$ \\
\hline$C_{\text {у ери }}$ & $-1.7454 * * *$ & $(0.6048)$ & $\beta_{\text {eри } \pi}$ & -0.0008 & $(0.0005)$ \\
\hline$C_{\text {ери ери }}$ & 0.1789 & $(0.6152)$ & $\beta_{\text {epuy }}$ & 0.0074 & $(0.0094)$ \\
\hline$\alpha_{\pi \pi}$ & $0.4991 * * *$ & $(0.0254)$ & $\beta_{\text {epu epu }}$ & $0.9506^{* * *}$ & $(0.0062)$ \\
\hline$\alpha_{\pi y}$ & $-0.9579 * * *$ & $(0.2841)$ & $\delta_{\pi \pi}$ & $0.8760 * * *$ & $(0.1566)$ \\
\hline$\alpha_{\pi \text { ери }}$ & $3.9722 * * *$ & $(1.1274)$ & $\delta_{\pi y}$ & -0.2352 & (0.6695) \\
\hline$\alpha_{y \pi}$ & 0.0086 & $(0.0061)$ & $\delta_{\pi e p u}$ & $-12.3266^{* * *}$ & $(2.7772)$ \\
\hline$\alpha_{y y}$ & $1.0543 * * *$ & $(0.0935)$ & $\delta_{y \pi}$ & $-0.0593 * * *$ & $(0.0160)$ \\
\hline$\alpha_{\text {уери }}$ & -0.1941 & $(0.1903)$ & $\delta_{y y}$ & $0.4575 * * *$ & $(0.0960)$ \\
\hline$\alpha_{\text {epu } \pi}$ & -0.0012 & $(0.0007)$ & $\delta_{\text {yepu }}$ & -0.0463 & $(0.3305)$ \\
\hline$\alpha_{\text {epu y }}$ & $-0.0220 * * *$ & $(0.0084)$ & $\delta_{\text {epu } \pi}$ & $0.0285^{* * *}$ & $(0.0042)$ \\
\hline$\alpha_{\text {epu ери }}$ & $-0.2108 * * *$ & $(0.0228)$ & $\delta_{e p u y}$ & 0.0016 & $(0.0114)$ \\
\hline$\beta_{\pi \pi}$ & -0.0269 & (0.0298) & $\delta_{e p u ~ e p u}$ & $0.1072 * *$ & $(0.0468)$ \\
\hline$\beta_{\pi y}$ & 0.3349 & $(0.2062)$ & & & \\
\hline
\end{tabular}

Note: Figures in parentheses against the coefficients are the Bollerslev et al. (1988) robust standard errors. $*, * *$ and $* * *$ indicate that the coefficients are significant at $10 \%, 5 \% \& 1 \%$ respectively. 
volatility indicating highly persistent nature of the variables under study. Regarding the spillovers effect for both innovations of shocks and conditional uncertainties, it revealed that there are significant cross effects and volatility transmissions among most of the series under reviewed. Specifically, global EPU volatility and inflation volatility is negatively correlated, while its lagged innovation has no material spillover effects on real uncertainty. Furthermore, significant asymmetric effects observe in most of the cases signify the asymmetric behaviour of volatility process. For example, all series are characterised by asymmetric innovations associated with their own conditional variances. They illustrate that positive shocks bring up larger volatility compared to negative shocks. The cross effects in most cases reflect leverage effects using the asymmetric multivariate GARCH model. Consequently, we find that besides the volatility feedback in most cases, especially of the global EPU, there are significant asymmetric volatility transmissions of macroeconomic uncertainty and global EPU to macroeconomic performance.

We conduct an array of specification checks (see panel A of Table 3) on the validity of the conditional mean and variance-covariance structure of the model. The specification tests indicate that the volatility process of the series is strongly conditionally heteroscedastic, with innovations to one series changes significantly affecting the conditional variance of the other series in an asymmetric manner. Overall, these specification checks confirm that the selected model does not bear significant misspecification errors and imply that the chosen specification form of the estimated model is superior compared to the other nested models (including the diagonal BEKK model). The asymmetric response of output to uncertainty shocks denotes that policy makers need to be more aggressive during bad than good times (see Gupta, Lau, \& Wohar, 2019).

It is more palatable to assume that Malaysia is an open economy and to account for the global nature of inflation. To this end, we replace the EPU variable with the US inflation in our model to account for cross-economy effect of the US on Malaysia; see Dungey and Osborn (2014). As discussed earlier, the predominance of US (in terms of trade and investments) over the other major advanced counties is clear. This is in common with the main findings of Ciccarelli and Mojon (2010) that global factors can explain around two thirds of the variance of inflation in 22 OECD countries. In a similar vein, Parker (2018) showed that by adding the global factor to Phillips curve can improve the forecasting performance but not for all countries. Parker revealed that country characteristics (high income, high financial development and better monetary policy) are correlated with high influence of global factors on national inflation rates. Precisely, Parker's results show that global factors explain about $66 \%$ of the variance of national inflation of the advanced economies, but only about $15-20 \%$ for the middleincome countries.

Next, we estimate the effect of global inflation uncertainty on macroeconomic performance by considering the role of US inflation. Inflation relates to price volatility and it affects EPU. Results reported in Table A1 (see Appendix) demonstrate the usual lagged effects of all series under review towards their levels as well as themselves (see Panel (a)). Considering the focal matrix of volatility transmissions (Panel (b) of Table A1), we uncover some noteworthy insights. The results firstly show that the impact of domestic macroeconomic uncertainty on macroeconomic performance are 
Table 3. Multivariate specification tests and residual diagnostics

Panel A: Specification tests for checking diagonality in mean and GARCH, GARCH effects and asymmetry

\begin{tabular}{ll}
\hline Diagonal VAR & $H_{0}: \Gamma_{12}{ }^{i}=\Gamma_{21}{ }^{i}=0, \quad i=1,2,3, \ldots, n, \quad \chi^{2}(30)=613.3158 \quad$ [0.0000] \\
No GARCH & $H_{0}: \alpha_{i j}=\beta_{i j}=\delta_{i j}=0, \quad$ for all $i, j ; \quad \chi^{2}(27)=176154.6494 \quad[0.0000]$ \\
No GARCH-M & $H_{0}: \psi_{i j}=0$, for all $i, j ; \quad \chi^{2}(9)=185.0032 \quad[0.0000]$ \\
Diagonal GARCH & $H_{0}: \alpha_{12}{ }^{i}=\alpha_{21}{ }^{i}=\beta_{12}{ }^{i}=\beta_{21}{ }^{i}=\delta_{12}{ }^{i}=\delta_{21}{ }^{i}=0, \quad i=1,2 \quad \chi^{2}(19)=442.4487 \quad[0.0000]$ \\
No Asymmetry & $H_{0}: \delta_{i j}=0$, for all $i, j ; \quad \chi^{2}(9)=338.0047 \quad[0.0000]$
\end{tabular}

Panel B:. Residuals diagnostics

\begin{tabular}{lcccccc}
\hline Residuals & \multicolumn{2}{c}{$\varepsilon_{n t}$} & \multicolumn{2}{c}{$\varepsilon_{y t}$} & \multicolumn{2}{c}{$\varepsilon_{\text {eput }}$} \\
\hline$Q_{4}$ & 7.9401 & {$[0.0938]$} & 6.8753 & {$[0.1426]$} & 0.2492 & {$[0.9929]$} \\
$Q_{8}$ & 14.7248 & {$[0.0647]$} & 9.3964 & {$[0.3100]$} & 0.5414 & {$[0.9998]$} \\
McLeod-Li: $Q_{4}$ & 5.4329 & {$[0.2457]$} & 6.9113 & {$[0.1407]$} & 0.1892 & {$[0.9958]$} \\
McLeod-Li: $Q_{8}$ & 6.2963 & {$[0.6141]$} & 11.1279 & {$[0.1946]$} & 4.1775 & {$[0.8408]$} \\
$A R C H(4)$ & 1.315 & {$[0.2654]$} & 1.591 & {$[0.1774]$} & 0.045 & {$[0.9960]$} \\
$A R C H(8)$ & 0.712 & {$[0.6804]$} & 1.216 & {$[0.2906]$} & 0.498 & {$[0.8570]$} \\
\hline
\end{tabular}

Multivariate residual diagnostics tests

\begin{tabular}{lrr}
\hline$Q_{4}$ & 31.75 & {$[0.6712]$} \\
$Q_{8}$ & 62.412 & {$[0.7828]$} \\
$A R C H(4)$ & 119.37 & {$[0.9336]$} \\
$A R C H(8)$ & 305.01 & {$[0.2349]$} \\
$\mathrm{LL}$ & -1465.26 &
\end{tabular}

Notes: The values in brackets are the p-values of the respective statistics. $Q_{p}$ and McLeod-Li are the $p^{\text {th }}$-order Ljung-Box $Q$ test statistics for correlation in standardised residuals and squared standardised residuals, respectively. $A R C H(\mathrm{~m})$ is the $\mathrm{m}^{\text {th }}$-order autoregressive conditional heteroscedasticity. LL shows the value of maximum log-likelihood criterion respectively. ${ }^{*}, * *$ and $* * *$ indicate that the coefficients are significant at the $10 \%, 5 \%$ and $1 \%$ levels respectively.

qualitatively similar to the ones reported earlier by Baharumshah and Soon (2014, p. 382). We observe a significant (negative) correlation between inflation and its uncertainty (-0.1033) as implied by Holland's (1995) hypothesis. Secondly, we observed a significant trade-off between the level of inflation and output volatility. Specifically, the model predicts that that a $1 \%$ increase in real uncertainty is followed by a decrease in domestic inflation by around $5 \%\left[\psi_{\pi y}=0.472 ; p\right.$-value $\left.=0.0198\right]$. Hence, it agrees with Taylor's hypothesis. Third, Malaysia's inflation uncertainty is significant at the usual significance levels. The negative coefficient sign indicates that inflation uncertainty is negatively correlated with output growth as postulated by Friedman (1977).

Macroeconomic volatility originating domestically is detrimental to economic growth, while it has a stabilising effect on inflation. More importantly, global shocks 
originating from the US has a different effect on Malaysia's macroeconomic performance. Specifically, we note that the estimated results change in a meaningful way when we use global uncertainty shocks. The distinctive feature of our results is that, on one hand, the magnitude of foreign shocks on domestic inflation and output growth is relatively larger compared to the influence of domestic nominal and real uncertainty. On the other hand, it is natural to assume that as an EM, Malaysia responds faster and more strongly to domestic nominal and real shocks only when we consider the impact of foreign policy shocks.

We now turn to uncertainty shocks that are associated with global inflation. To this end, the US inflation is used to proxy global inflation because of Malaysia's high dependence on the US economy. ${ }^{13}$ It is broadly recognised that commodity prices and inflation are closely linked. Without going into details, we know that the effects of an economic slowdown are felt across the globe in the follow-up to the turmoil of financial markets and rising commodities prices. Despite the broad consensus about slowing growth, there is signifcant uncertainty with regard to the response of inflation to rising commondity prices. Expansion of the global value chains (i.e., cross-border trade in intermediate goods and services) is an important channel through which global economic slack influences domestic inflation. In other words, the impact of (global) inflation on middle and lower income countries is still an open question. Theory predicts that higher home country inflation increases exchange rate volatility, especially for EMs/developing economies. This is because their central banks are less credibe compared to the more advanced countries. The expansion of global value chains (GVCs), that is, cross-border trade in intermediate goods and services, and global economic slacks are increasingly influencing domestic inflation. This empirical correlation between global economic slack and domestic inflation exists across countries and over time. Therefore, our results tend to support that domestic macroeconomic dynamics are becoming more sensitive to international disturbances of productivity, demand and hence inflation.

This paper finds that that global EPU is positively affecting Malaysian macroeconomic performance such that it has a strong positive impact on domestic inflation. This theme of estimated results illustrates a broad similarity in pattern of responses to both domestic and global EPU uncertainty shocks. According to Ciccarelli and Mojon (2010), none of the OECD countries can claim that they are immune from global inflation shocks. This triggers an idea that central banks are unable to fully control the trend in inflation because inflation in any one country is driven to a large extend by global factors, which are outside their control. The estimated results endorse a positive volatility-growth nexus as suggested by Black (1987) for considering global inflation and exhibit the negatively insignificant evidence for the negative volatilitygrowth phenomenon as elaborated by Pindyck (1991). More importantly, domestic

13 Instead of global inflation, we can look at the impact of the US EPU on Malaysia's output and inflation. A reduction in the EPU tends to directly lower Malaysia's CPI-inflation. US EPU shock heightened domestic EPU through the trade channel and it can exert inflationary pressures, putting price stability at risk. Colombo (2013) demonstrated this by showing that the contribution of US uncertainty shock is larger than that of the Euro-area specific shocks. We are grateful to a referee for pointing this to us. 
macroeconomic volatility is detrimental to real economic growth in the study area, while it has a stabilising effect on higher inflation.

Evidently, our main results are consistent with the existing literature (Aastveit et al., 2016; Erten, 2012) that emphasised the impact of global shocks on business cycle fluctuations. We observe for the first time a strong and positive correlation between global inflation and macroeconomic uncertainty. The estimated correlation coefficient from the model lends support to Berger, Grabert and Kampa's (2017) argument regarding the global dimension of uncertainty. Precisely, they claimed that the recessions in the early 1970s and early 1980 plus the Great Recession of the late 2000 s in the OECD to be linked with increases in both inflation and economic growth uncertainties on a global scale. According to the dynamic factor model the Great Moderation that started in the mid-1980s in the OECD countries is characterised by a discernible slowdown of global uncertainty which in their words are "not matched by a comparable reduction in the incidence of national uncertainty" (p. 43).

The covariance matrix (Table $A 2$ ) tends to support the aforementioned empirical findings. The diagonal and off-diagonal coefficients of the A and B matrices are statistically significant at the usual levels, with minor exceptions. Innovations in nominal and real uncertainties have significant effect on inflation. Nominal uncertainty accelerates domestic inflation compared to the stabilisation effect of real uncertainty (as well as global inflationary shocks). Also worth mentioning, global inflationary shock has a positive link with domestic uncertainty shocks. It is evident that nominal uncertainty shocks positively affect domestic macroeconomic variables. Our results demonstrate that omitting the cross-effect between domestic and foreign inflation rates may in fact bias the estimates and lead to misleading policy conclusions. The estimated models are free from any misspecification issues (see Panels (a) and (b)of Table A3). There is no evidence of remaining ARCH effects and the specification is free from autocorrelations. Finally, we note that our results (unreported) are robust to the exclusion of the 2008-09 GFC sample periods. In other words, the shorter sample period tends to replicate our main findings, with no drastic change (decrease) in conditional correlation. To save space, we choose not to report the results here but is available upon request from the authors.

\section{Conclusions}

There is considerable interest in studying the impact of uncertainty on macroeconomic variables. The results from the BEKK-GARCH-M model confirm that an elevated uncertainty originating from the US adversely affects real economic activities. The destabilising effect squares with the predictions of the real options theory, that is, excessive uncertainty has a negative and significant effect on economic activities and other macro data. For the uncertainty-inflation nexus, the outcomes from the preferred specification verify that an increased in foreign inflation uncertainty raises the domestic CPI-inflation rate. Clearly, the latter result supports the notion that external factors are important and explain an increasing proportion of the variation in domestic inflation. This accords with the idea that the Great Moderation is attributed to various global causes like improved monetary policy, better inventory management 
techniques, good luck theory (e.g., smaller oil price shocks), and less severe global shocks hitting the global economy. Since the rise and fall in the level (and volatility) of inflation is more of a global phenomenon, policymakers have to focus more on global development. Thus, like many of the OECD countries, our findings underline the idea that EMs can benefit from international policy coordination in an interconnected global environment. Through the lens of the multivariate GARCH model, we report that the spillover effects from domestic inflation and output uncertainty on a country's output level are insignificant at the usual significant levels, after controlling for global EPU. Similar to Liow et al.'s (2018) work, we discover that uncertainties across countries are interrelated via linkages that exist in a globlised world. We consider this an important result and policymakers (particularly in the EMs) can no longer ignore the importance of foreign uncertainty.

The fact that EMs is vulnerable to fluctuations in EPU that has its origin from major economies denotes that uncertainty has a prominent place in policy calculus. After shifting from fixed to manage float exchange rate system, Malaysia is now more expose to external shocks. It is important to apprehend the slowdown is largely due to the wait-and-see policy for investment adopted by firms. After the uncertainty is resolve, it can create a temporarily investment boom. On this final note, policies might include measures aim at reducing uncertainty in order to mitigate its impact on the overall economy. The central question for policy in EMs is how to stabilise the economy in response to external shocks. Given the role attached to foreign shocks as documented in the present and prior papers, future studies may extend the empirical analysis to look at the impact of global EPU on other fundamentals such interest rates, exchange rates and debts. A natural fruitful extension would be to analyse the spillovers between Malaysia, China, Japan and the US to indicate whether spillover of uncertainty exists between them. We may apply other econometric methods to test for the validity of the uncertainty spillovers hypothesis across the globe. This is in our current research agenda.

\section{References}

Aastveit, K., Bjørnland, H.C., \& Thorsrud, L.A. (2016). The world is not enough! Small open economies and regional dependence. Scandinavian Journal of Economics, 118(1), 168-195, https://doi.org/10.1111/sjoe.12126

Akinci, Ö. (2013). Global financial conditions, country spreads and macroeconomic fluctuations in emerging countries. Journal of International Economics, 92(2), 358-371. https://doi.org/ 10.1016/j.jinteco.2013.07.005

Baharumshah, A.Z., Chan, T-H., \& Fountas, S. (2002). Re-examining purchasing power parity for East-Asian currencies: 1976-2002. Applied Financial Economics, 18(1), 75-85. https://doi. org/10.1080/09603100601018856

Baharumshah, A.Z., \& Soon, S.-V. (2014). Inflation, inflation uncertainty and output growth: What does the data says for Malaysia? Journal of Economic Studies, 41(3), 370-386. https://doi. org/10.1108/JES-05-2012-0073

Baker, S.R., Bloom, N., \& Davis, S.J. (2016). Measuring economic policy uncertainty. Quarterly Journal of Economics, 131(4), 1593-1636. https://doi.org/10.1093/qje/qjw024

Balli, F., Hajhoj, H.R., Basher, S.A., \& Belkacem, H. (2015). An analysis of returns and volatility spillovers and their determinants in emerging Asian and Middle Eastern countries. International 
Review of Economics \& Finance, 39(September), 311-325. https://doi.org/10.1016/j.iref. 2015.04.013

Baum, C.F., Chakraborty, A. Han, L., \& Liu, B. (2011). The effects of uncertainty and corporate governance on firms' demand for liquidity. Applied Economics, 44(4), 515-525. https://doi. org/10.1080/00036846.2010.508733

Berger, T., Grabert, S., \& Kempa, B. (2017). Global macroeconomic uncertainty. Journal of Macroeconomics, 53(September), 42-56. https://doi.org/10.1016/j.jmacro.2017.05.005

Bernanke, B.S. (1983). Irreversibility, uncertainty and cyclical investments. Quarterly Journal of Economics, 98(1), 85-106. https://doi.org/10.2307/1885568

Black, F. (1987). Business cycles and equilibrium. New York, NY: Basil Blackwell.

Bloom, N. (2009). The impact of uncertainty shocks. Econometrica, 77(3), 623-685. https://doi. org/10.3982/ECTA6248

Bollerslev, T., Engle, R.F., \& Wooldridge, J.M. (1988). A capital asset pricing model with timevarying covariances. Journal of Political Economy, 96(1), 116-131.

Bredin, D., Elder, J., \& Fountas, S. (2009). Macroeconomic uncertainty and performance in Asian countries. Review of Development Economics, 13(2), 215-229. https://doi.org/10.1111/ j.1467-9361.2009.00508.x

Caldara, D., Fuentes-Albero, C., Gilchrist, S., \& Zakrajšek, E. (2016). The macroeconomic impact of financial and uncertainty shocks. European Economic Review, 88(September), 185-207. https://doi.org/10.1016/j.euroecorev.2016.02.020

Choi, S. (2018). The impact of US financial uncertainty shocks on emerging market economies: An international credit channel. Open Economies Review, 29(1), 89-118. https://doi. org/10.1007/s11079-017-9471-y

Choi, S., \& Shim, M. (2019). Financial vs. policy uncertainty in emerging economies: Evidence from Korea and the BRICs. Open Economies Review, 30(2), 297-318. https://doi.org/10.2139/ ssrn.2862500

Choi, S., Furceri, D., Huang, Y., \& Loungani, P. (2018). Aggregate uncertainty and sectoral productivity growth: The role of credit constraints. Journal of International Money and Finance, 88(November), 314-330. https://doi.org/10.1016/j.jimonfin.2017.07.016

Ciccarelli, M., \& Mojon, B. (2010). Global inflation. Review of Economics and Statistics, 92(3), 524535.

Colombo, V. (2013). Economic policy uncertainty in the US: Does it matter for the Euro area? Economics Letters, 121(1), 39-42. https://doi.org/10.1016/j.econlet.2013.06.024

Demir, E., \& Ersan, O. (2017). Economic policy uncertainty and cash holdings: Evidence from BRIC countries. Emerging Markets Review, 33(December) 189-200. https://doi.org/10.1016/j. ememar.2017.08.001

Dungey, M., \& Osborn, D.R. (2014). Modelling large open economies with international linkages: The USA and Euro area. Journal of Applied Econometrics, 29(3), 377-393. https://doi.org/ 10.1002/jae.2323

Engle, R.F., \& Kroner, K.F. (1995). Multivariate simultaneous Generalized ARCH. Econometric Theory, 11(1), 122-150.

Erten, B. (2012). Macroeconomic transmission of Eurozone shocks to emerging economies. International Economics, 131(March), 43-70. https://doi.org/10.1016/S2110-7017(13)60054-2

Fontaine, I., Didier, L., \& Razafindravaosolonirina, J. (2017). Foreign policy uncertainty and US macroeconomic activity: Evidence from China. Economics Letters, 155(June), 121-125. https://doi.org/10.1016/j.econlet.2017.03.034

Friedman, M., (1977). Nobel lecture: Inflation and unemployment. Journal of Political Economy, 85(3), 451-472.

Grier, K.B., Henry, Ó.T., Olekalns, N., \& Shields, K. (2004). The asymmetric effects of uncertainty on inflation and output growth. Journal of Applied Econometrics 19(5), 551-565. https://doi. org/10.1002/jae.763 
Gulen, H., \& Ion, M. (2016). Policy uncertainty and corporate investment. Review of Financial Studies, 29(3), 523-564. https://doi.org/10.1093/rfs/hhv050

Gupta, R., Lau, C-K-M., \& Wohar, M.E. (2019). The impact of US uncertainty on the Euro area in good and bad times: Evidence from a quantile structural vector autoregressive model. Empirica, 46(2), 353-368. https://doi.org/10.1007/s10663-018-9400-3

Holland, A.S. (1995). Inflation and uncertainty: Tests for temporal ordering. Journal of Money, Credit and Banking, 27(3), 827-837. https://doi.org/10.2307/2077753

Hoque, M.E., \& Zaidi, M.A.S. (2019). The impacts of global economic policy uncertainty on stock market returns in regime switching enviroment: Evidence from sectoral perspective. International Journal of Finance \& Economics, 24(2), 991-1016. https://doi.org/10.1002/ ijfe.1702

Istiak, K., \& Serletis, A. (2018). Economic policy uncertainty and real output: Evidence from the G7 countries. Applied Economics, 50(39): 4222-4233. doi.org/10.1080/00036846.2018.1441520

Jones, P.M., \& Olson, E. (2013). The time-varying correlation between uncertainty, output, and inflation: Evidence from a DCC-GARCH model. Economics Letters, 118(1), 33-37. https://doi. org/10.1016/j.econlet.2012.09.012

Jouini, J., \& Harrathi. N. (2014). Revising the shock and volatility transmissions among GCC stock and oil markets: A further investigation. Economic Modelling, 38(February), 486-494. https:// doi.org/10.1016/j.econmod.2014.02.001

Jurado, K., Ludvigson, S.C., \& Ng, S. (2015). Measuring Uncertainty. American Economic Review, 105(3), 1177-1216. https://doi.org/10.1257/aer.20131193

Krol, R. (2014). Economic policy uncertainty and exchange rate volatility. International Finance, 17(2), 241-256. https://doi.org/10.1111/infi.12049

Leduc, S., \& Liu, Z. (2016). Uncertainty shocks are aggregate demand shocks. Journal of Monetary Economics, 82(September), 20-35. https://doi.org/10.1016/j.jmoneco.2016.07.002

Liow, K.H., Liao, W.-C., \& Huang, Y. (2018). Dynamics of international spillovers and interaction: Evidence from financial markets stress and economic policy uncertainty. Economic Modelling, 68(January), 96-116. https://doi.org/10.1016/j.econmod.2017.06.012

Maćkowiak, B. (2007). External shocks, U.S. monetary policy and macroeconomic fluctuations in emerging markets. Journal of Monetary Economics, 54(8), 2512-2520. https://doi. org/10.1016/j.jmoneco.2007.06.021

Mumtaz, H., \& Surico, P. (2018). Policy uncertainty and aggregate fluctuations. Journal of Applied Econometrics, 33(3), 319-331. https://doi.org/10.1002/jae.2613

Mumtaz, H., \& Theodoridis, K. (2015). The international transmission of volatility shocks: An empirical analysis. Journal of the European Economic Association, 13(3), 512-533. https://doi. org/10.1111/jeea.12120

Munir, Q., Kok, S.C., Lean H.H., \& Teplova, T. (2018). Purchasing power parity in ASEAN-5 countries: Revisit with cross-sectional dependence and structural breaks. Macroeconomics and Finance in Emerging Market Economies, 11(3), 233-249. https://doi.org/10.1080/17520843. 2018.1505760

Ozturk, E.O., \& Sheng, X.S. (2018). Measuring global and country-specific uncertainty. Journal of International Money and Finance, 88(November), 276-295. https://doi.org/10.1016/j. jimonfin.2017.07.014

Parker, M. (2018). How global is global inflation? Journal of Macroeconomics, 58(December), 174197. https://doi.org/10.1016/j.jmacro.2018.09.003

Pindyck, R.S. (1991). Irreversibility, uncertainty, and investment. Journal of Economic Literature, 29(3), 1110-1148.

Raghavan, M., \& Athanasopoulos, G. (2019). Analysis of shock transmissions to a small open emerging economy using a SVARMA model. Economic Modelling, 77(March), 187-203. https://doi.org/10.1016/j.econmod.2018.09.004 
Shah, S.Z., Baharumshah, A.Z., Law, S.H., \& Habibullah, M.S. (2017). Nominal uncertainty, real uncertainty and mecroeconomic performance in a time-varying asymmetric framework: implication for monetray policy. Research in International Business and Finance, 42(December), 75-93. https://doi.org/10.1016/j.ribaf.2017.05.012

Song, K.R., \& Song, Y.L. (2012). Long-term effects of a financial crisis: Evidence from cash holding of East Asian firms. Journal of Financial and Quantitative Analysis, 47, 617-641. https://doi. org/10.1017/S0022109012000142

Trung, N.B. (2019). The spillover effects of US policy uncertainty on the global economy: A global VAR approach. North American Journal of Economics and Finance, 48(April), 90-110. https:// doi.org/10.1016/j.najef.2019.01.017

Tsai, I-C. (2017). The source of global stock market risk: A view point of economic policy uncertainty. Economic Modelling, 60(January), 122-131. https://doi.org/10.1016/j.econmod. 2016.09.002

Zhang, D., Lei, L., Ji, Q., \& Kutan, A.M. (2019). Economic policy uncertainty in the US and China and their impact on the global markets. Economic Modelling, 79(June), 47-56. https://doi. org/10.1016/j.econmod.2018.09.028 


\section{Appendix: Robustness checks using global inflation as measure of global policy uncertainty}

Table A1. Estimates of asymmetric VAR-BEKK-GARCH-M models (1997.01-2016.12)

Panel (a): Estimates of conditional mean equations

\begin{tabular}{lllllll}
\hline Mean Eq. & \multicolumn{2}{c}{$\pi_{t}$} & \multicolumn{2}{c}{$y_{t}$} & \multicolumn{2}{c}{$e p u_{t}$} \\
\hline Constant & $0.0374 * * *$ & $(0.0139)$ & $0.6012^{*}$ & $(0.3333)$ & $0.1750^{* * *}$ & $(0.0200)$ \\
$\pi_{t-1}$ & $0.3731^{* * *}$ & $(0.0654)$ & $-0.5851^{* *}$ & $(0.3860)$ & $0.2120^{* * *}$ & $(0.0630)$ \\
$y_{t-1}$ & -0.0034 & $(0.0032)$ & $-0.3222^{* * *}$ & $(0.0626)$ & $0.0188^{* * *}$ & $(0.0060)$ \\
$e p u_{t-1}$ & 0.0248 & $(0.0531)$ & -0.5183 & $(0.3672)$ & -0.0420 & $(0.0794)$
\end{tabular}

Panel (b): The estimated values of the uncertainty matrix $(\psi)$

\begin{tabular}{lll}
\hline$\psi_{\pi \pi}$ & $-0.1033^{* * *}$ & $(0.0384)$ \\
$\psi_{\pi y}$ & $-0.0472^{* *}$ & $(0.0198)$ \\
$\psi_{\text {пери }}$ & $2.5122^{* * *}$ & $(0.5062)$ \\
$\psi_{\text {у }}$ & $-0.3220^{* * *}$ & $(0.0964)$ \\
$\psi_{\text {yy }}$ & -0.0604 & $(0.0473)$ \\
$\psi_{\text {уери }}$ & $3.3274 * * *$ & $(0.4812)$ \\
$\psi_{\text {ери } \pi}$ & $1.8490^{* * *}$ & $(0.4278)$ \\
$\psi_{\text {ери }}$ & $0.2521 * * *$ & $(0.0630)$ \\
$\psi_{\text {ери ери }}$ & $-2.0611^{* * *}$ & $(0.3052)$
\end{tabular}

Note: Figures in parentheses against the coefficients are the Bollerslev et al. (1988) robust standard errors. $*,{ }^{* *}$ and ${ }^{* * *}$ indicate that the coefficients are significant at $10 \%, 5 \% \& 1 \%$ respectively.

Table A2. Estimates of the variance-covariance equations

\begin{tabular}{|c|c|c|c|c|c|}
\hline$C_{\pi \pi}$ & 0.0420 & (0.0398) & $\beta_{\text {пери }}$ & -0.0224 & (0.0180) \\
\hline$C_{\pi y}$ & 0.0902 & $(0.1164)$ & $\beta_{y \pi}$ & $0.0221 * *$ & (0.0098) \\
\hline$C_{y y}$ & $1.9182 * * *$ & $(0.0869)$ & $\beta_{y y}$ & $-0.1574 * * *$ & $(0.0602)$ \\
\hline$C_{\text {пери }}$ & $0.0998 * * *$ & $(0.0294)$ & $\beta_{\text {уери }}$ & $0.0618 * * *$ & $(0.0063)$ \\
\hline$C_{\text {y ери }}$ & $0.0554 * * *$ & $(0.0176)$ & $\beta_{\text {ери } \pi}$ & $-0.3236 * *$ & (0.1392) \\
\hline$C_{\text {ери ери }}$ & 0.0278 & $(0.0280)$ & $\beta_{\text {epu y }}$ & $-1.1656^{*}$ & (0.6116) \\
\hline$\alpha_{\pi \pi}$ & $1.0980 * * *$ & $(0.1252)$ & $\beta_{\text {ери ери }}$ & $0.3222 * * *$ & $(0.1236)$ \\
\hline$\alpha_{\pi y}$ & $-1.9288 * * *$ & $(0.2766)$ & $\delta_{\pi \pi}$ & $-1.5976 * * *$ & (0.2796) \\
\hline$\alpha_{\pi е р u}$ & $-0.0606 * * *$ & $(0.0160)$ & $\delta_{\pi y}$ & -0.1936 & (1.1090) \\
\hline$\alpha_{y \pi}$ & $0.0282 * * *$ & $(0.0084)$ & $\delta_{\text {пери }}^{\text {й }}$ & $-0.2917 * * *$ & (0.0508) \\
\hline$\alpha_{y y}$ & $0.2507 * * *$ & $(0.0753)$ & $\delta_{y \pi}$ & $0.0193 * * *$ & $(0.0056)$ \\
\hline$\alpha_{\text {уери }}$ & $0.0158 * * *$ & $(0.0042)$ & $\delta_{y y}$ & $0.6924 * * *$ & (0.0820) \\
\hline$\alpha_{e p u \pi}$ & $0.4672 * * *$ & (0.0929) & $\delta_{\text {у ери }}$ & $0.0357 * * *$ & $(0.0080)$ \\
\hline$\alpha_{\text {epu y }}$ & $1.0722 * *$ & $(0.4670)$ & $\delta_{\text {ери } \pi}$ & 0.0327 & (0.0696) \\
\hline$\alpha_{\text {ери ери }}$ & $0.3368 * * *$ & $(0.0353)$ & $\delta_{\text {epuy }}$ & $-4.8287 * * *$ & (0.8228) \\
\hline$\beta_{\pi \pi}$ & $0.0905^{* *}$ & $(0.0410)$ & $\delta_{\text {ери ери }}$ & $0.3739 * * *$ & (0.0738) \\
\hline$\beta_{\pi y}$ & 0.0849 & $(0.1184)$ & & & \\
\hline
\end{tabular}

Note: Figures in parentheses against the coefficients are the Bollerslev et al. (1988) robust standard errors. $*, * *$ and $* * *$ indicate that the coefficients are significant at $10 \%, 5 \% \& 1 \%$ respectively. 
Table A3. Multivariate specification tests and residual diagnostics

Panel (a): Specification tests for checking diagonality in mean and GARCH, GARCH effects and asymmetry

\begin{tabular}{ll}
\hline Diagonal VAR & $H_{0}: \Gamma_{12}{ }^{i}=\Gamma_{21}{ }^{i}=0 \quad i=1,2,3, \ldots . n, \chi^{2}(6)=34.6198 \quad[0.0000]$ \\
No GARCH & $H_{0}: \alpha_{i j}=\beta_{i j}=\delta_{i j}=0$, for all $i, j ; \quad \chi^{2}(27)=4779.4338 \quad[0.0000]$ \\
No GARCH-M & $H_{0}: \psi_{i j}=0$, for all $i, j ; \quad \chi^{2}(9)=130.8686 \quad[0.0000]$ \\
Diagonal GARCH & $H_{0}: \alpha_{12}{ }^{i}=\alpha_{21}{ }^{i}=\beta_{12}{ }^{i}=\beta_{21}{ }^{i}=\delta_{12}{ }^{i}=\delta_{21}{ }^{i}=0, \quad i=1,2 ; \quad \chi^{2}(18)=1503.1822 \quad[0.0000]$ \\
No Asymmetry & $H_{0}: \delta_{i j}=0$, for all $i, j ; \quad \chi^{2}(9)=459.5374 \quad[0.0000]$
\end{tabular}

Panel (b): Residuals diagnostics

\begin{tabular}{lllllrl}
\hline Residuals & \multicolumn{2}{c}{$\varepsilon_{\pi t}$} & \multicolumn{2}{c}{$\varepsilon_{y t}$} & \multicolumn{2}{c}{$\varepsilon_{\text {eput }}$} \\
\hline$Q_{4}$ & 1.511 & {$[0.8247]$} & 3.4560 & {$[0.4860]$} & 11.4270 & {$[0.0222]$} \\
$Q_{8}$ & 6.479 & {$[0.5938]$} & 8.0284 & {$[0.4307]$} & 18.4829 & {$[0.0179]$} \\
McLeod-Li: $Q_{4}$ & 3.201 & {$[0.5248]$} & 2.4706 & {$[0.6499]$} & 4.1930 & {$[0.3805]$} \\
McLeod-Li: $Q_{8}$ & 4.809 & {$[0.8090]$} & 3.9939 & {$[0.8577]$} & 20.4433 & {$[0.0088]$} \\
$A R C H(4)$ & 0.724 & {$[0.5764]$} & 0.573 & {$[0.6825]$} & 1.112 & {$[0.3516]$} \\
$A R C H(8)$ & 0.606 & {$[0.7720]$} & 0.428 & {$[0.9032]$} & 2.215 & {$[0.0274]$} \\
\hline
\end{tabular}

Multivariate residual diagnostics tests

\begin{tabular}{lrl}
\hline$Q_{4}$ & 40.307 & {$[0.2855]$} \\
$Q_{8}$ & 81.549 & {$[0.2066]$} \\
$A R C H(4)$ & 135.88 & {$[0.6730]$} \\
$A R C H(8)$ & 344.12 & {$[0.0129]$} \\
$L L$ & -501.02 & \\
\hline
\end{tabular}

Notes: $* * *$ and $* * *$ indicate that the coefficients are significant at the $10 \%, 5 \%$ and $1 \%$ levels respectively. Also, see note to Table 3. 
